Brit. Heart f., 1967, 29, 512.

\title{
Electrocardiographic Response to Selective Coronary Arteriography
}

\author{
RICHARD L. COSKEY AND OSCAR MAGIDSON \\ From the Cardio-pulmonary Laboratory, St. Vincent's Hospital, Los Angeles, California, U.S.A.
}

Selective opacification of the coronary arteries offers a singular opportunity to study the pathological anatomy of coronary artery disease in intact humans. Littmann (1962), Ross (1963), and Likoff et al. (1964) have noted electrocardiographic responses associated with selective coronary opacification in man, but no comprehensive study of these changes appears to have been made. This report is based on a review of electrocardiographic changes in 71 patients during bilateral selective coronary artery opacification.

\section{SUBJECTS AND MeThODS}

The 71 patients ranged in age from 27 to 69 years (Table I). They were studied in order to establish the presence or absence of discernible coronary artery disease as a cause of their chest pain and/or abnormal electrocardiograms, or to help define the ætiology of chest pain in a patient with valvular (usually aortic) heart disease, or, in two cases, congenital heart disease. Coronary arteriography was carried out on 46 patients to confirm or exclude the presence of isolated coronary artery disease; 15 patients had primary aortic valve disease, 6 had primary mitral valve disease, one had an atrial septal defect (secundum type), and one had a cardiomyopathy of undetermined xtiology.

Selective left and right coronary arteriography was performed by the technique of Sones and Shirey (1962). Opacification was obtained by injection of warm $\mathrm{Hy}-$ paque $R$ through a No. 7 or No. 8 Sones catheter into the ostium of the coronary artery. The concentration varied between 70 and 90 per cent. Continuous electrocardiographic monitoring was recorded during and following the contrast injection. In 43 patients, only lead II was recorded. In 28 patients, leads I, II, and III were simultaneously recorded. Cine-arteriograms were recorded on $35 \mathrm{~mm}$. film at 60 frames/sec. using a $6 \mathrm{in}$. image intensifier, and the films were assessed on a Tage-Arno $35 \mathrm{~mm}$. viewer.

Six patients in whom only one coronary artery was selectively opacified were not included in this series.

Received February 10, 1966.

\section{RESULTS}

The electrocardiographic responses to selective injection of contrast media are characterized by changes typical of left coronary artery or right coronary artery injection, or, in 15 cases, a synthesis of the changes seen in left and right coronary artery injections. These changes will be termed left coronary artery response, right coronary artery response, and bilateral coronary artery response, respectively. In no case did left coronary opacification produce a right coronary artery response.

The relation between electrocardiographic response and coronary artery abnormalities, as demonstrated by cine-arteriography, is shown in Table II. Of the 57 patients $(30 \%)$ with left coronary artery response to selective opacification, 17 had arteriographic abnormalities of one or both coronary arteries. These lesions ranged from slight plaque formation to complete occlusion. Only 2 of the 15 patients $(13 \%)$ with bilateral coronary artery response had normal coronary arteries, as noted on cine-arteriography. One of these 2 patients was later found at operation to have marked narrowing of the right coronary artery ostium, which was not evident on the coronary arteriogram. In only one of the 15 patients (7\%) with bilateral coronary artery response was the presence of significant coronary artery obstruction not evident.

Electrocardiographic data from all the 71 patients are given in Table III. Two consecutive electrocardiographic shifts, involving the QRS complex, ST segment, and $T$ waves, were demonstrated in 15 patients during opacification of one coronary artery (to be discussed later), and are not included in the tabulations of the QRS, ST, and T wave shifts of that specific vessel. The contralateral coronary artery injections in these 15 patients were not distinguishable from the other patients (except for $T$ wave changes as noted below) and are, therefore, included in the tabulation. All patients are 
TABLE I

AGE DISTRIBUTION AS RELATED TO CORONARY ARTERY PATHOLOGY DEMONSTRATED BY SELECTIVE CORONARY ARTERIOGRAPHY

\begin{tabular}{c|c|c|c|c|c|}
\hline & \multicolumn{5}{|c|}{ Coronary arteriograms } \\
\cline { 2 - 6 } Age (yr.) & $\begin{array}{c}\text { Normal left } \\
\text { and right }\end{array}$ & $\begin{array}{c}\text { Abnormal } \\
\text { left }\end{array}$ & $\begin{array}{c}\text { Abnormal } \\
\text { right }\end{array}$ & $\begin{array}{c}\text { Abnormal left } \\
\text { and right }\end{array}$ & $\begin{array}{c}\text { No. of } \\
\text { patients }\end{array}$ \\
\hline 27 & 1 & 0 & 0 & 0 & 1 \\
$31-40$ & 11 & 1 & 0 & 6 & 18 \\
$41-50$ & 19 & 1 & 2 & 7 & 20 \\
$51-60$ & 7 & 5 & 1 & 2 & 6 \\
$61-69$ & 4 & 0 & 0 & 19 & 71 \\
\hline Total & 42 & 7 & 3 & & 2 \\
\hline
\end{tabular}

TABLE II

CLASSIFICATION OF ELECTROCARDIOGRAPHIC RESPONSE TO SELECTIVE CORONARY ARTERY OPACIFICATION AS RELATED TO CORONARY ARTERY PATHOLOGY DEMONSTRATED BY SELECTIVE CORONARY ARTERIOGRAPHY

\begin{tabular}{|c|c|c|c|c|c|}
\hline \multirow[b]{2}{*}{ Electrocardiographic response } & \multicolumn{4}{|c|}{ Coronary arteriograms } & \multirow[b]{2}{*}{$\begin{array}{l}\text { No. of } \\
\text { patients }\end{array}$} \\
\hline & $\begin{array}{l}\text { Normal left } \\
\text { and right }\end{array}$ & $\begin{array}{c}\text { Abnormal } \\
\text { left }\end{array}$ & $\begin{array}{c}\text { Abnormal } \\
\text { right }\end{array}$ & $\begin{array}{l}\text { Abnormal left } \\
\text { and right }\end{array}$ & \\
\hline $\begin{array}{l}\text { Right coronary artery opacification } \\
\text { Right coronary artery response } \\
\text { Bilateral response }\end{array}$ & $\begin{array}{r}42 \\
0\end{array}$ & $\begin{array}{l}6 \\
1 \\
\end{array}$ & $\begin{array}{l}3 \\
0\end{array}$ & $\begin{array}{r}19 \\
0\end{array}$ & $\begin{array}{r}70 \\
1\end{array}$ \\
\hline Total & 42 & 7 & 3 & 19 & 71 \\
\hline $\begin{array}{l}\text { Left coronary artery opacification } \\
\text { Left coronary artery response } \\
\text { Bilateral response }\end{array}$ & $\begin{array}{r}40 \\
2\end{array}$ & $\begin{array}{l}6 \\
1\end{array}$ & $\begin{array}{l}2 \\
1\end{array}$ & $\begin{array}{r}9 \\
10\end{array}$ & $\begin{array}{l}57 \\
14 \\
\end{array}$ \\
\hline Total & 42 & 7 & 3 & 19 & 71 \\
\hline
\end{tabular}

included in the data relating to QT interval and heart rate.

$P$ Waves. Three patients had atrial fibrillation and are, therefore, not included in the tabulation. A transient decrease in $\mathbf{P}$ wave amplitude occurred in approximately one-fifth of those with normal coronary arteriograms, and about twice as frequently in patients with abnormal coronary arteriograms. The decrease in $\mathbf{P}$ wave amplitude seemed greatest in association with the most marked $T$ wave shifts. A transient increase in $\mathrm{P}$ wave amplitude was noted in only one patient, a 42-year-old man with a secundum type atrial septal defect, large left-toright shunt, and normal coronary arteriograms; the increase in $\mathbf{P}$ wave amplitude occurred during left coronary artery opacification only. No changes in $\mathbf{P}$ wave configuration were noted.

Mean Frontal QRS Vector. Vector shifts were related to the entire QRS complex or the terminal vector. In no case was only the initial vector involved. Right coronary artery opacification produced a rightward shift of the mean QRS axis in 89 per cent of patients, characterized by decreased positive $Q R S$ voltage in lead I and increased voltage in lead III. In the remaining patients, no QRS shift was evident. Left coronary artery opacification produced a leftward shift of the mean QRS axis in 68 per cent of patients, characterized by an increase in positive QRS voltage in lead I and decreased positive voltage in lead III. In the remaining patients, no QRS shift was evident.

Mean Frontal QRS Amplitude. Right coronary artery opacification produced an increase in mean frontal QRS amplitude in 64 per cent of patients, and no amplitude changes were noted in the remainder. Left coronary artery opacification produced an increase in mean frontal QRS amplitude in 32 per cent of patients. None of the 5 patients with an arteriographically abnormal left coronary artery demonstrated a significant increase in mean frontal QRS amplitude. In no case was a decrease in amplitude evident.

Amplitude of $Q R S$ in Lead II. Right coronary artery opacification produced an increase in the amplitude of QRS in lead II in 64 per cent of patients, and the amplitude was unchanged in the remainder. Amplitude increase was more frequent in patients with normal coronary arteries. A change 
PARAMETERS OF ELECTROCARDIOGRAPHIC OPACIFICATION AS RELATED TO NORMAL PERCENTAGES OF PATIENTS DEMON-

\begin{tabular}{|c|c|c|c|c|c|c|c|c|c|c|c|c|c|c|}
\hline & \multicolumn{2}{|c|}{\begin{tabular}{|l|} 
Amplitude of \\
$\mathbf{P}$ in lead II
\end{tabular}} & \multicolumn{3}{|c|}{ QRS vectort } & \multicolumn{3}{|c|}{$\begin{array}{l}\text { QRS vector } \\
\text { amplitudet }\end{array}$} & \multicolumn{3}{|c|}{$\begin{array}{c}\text { Amplitude of } \\
\text { QRS in lead II } \neq \S\end{array}$} & \multicolumn{3}{|c|}{ ST vectort } \\
\hline & $\begin{array}{l}\text { Node- } \\
\text { crease }\end{array}$ & $\begin{array}{c}\text { De- } \\
\text { crease }\end{array}$ & $\begin{array}{c}\text { No } \\
\text { change }\end{array}$ & $\begin{array}{l}\text { Left- } \\
\text { ward }\end{array}$ & $\begin{array}{l}\text { Right- } \\
\text { ward }\end{array}$ & $\begin{array}{c}\text { No } \\
\text { change }\end{array}$ & $\begin{array}{c}\text { In- } \\
\text { crease }\end{array}$ & $\begin{array}{c}\text { De- } \\
\text { crease }\end{array}$ & $\begin{array}{l}\text { No } \\
\text { change }\end{array}$ & $\begin{array}{c}\text { In- } \\
\text { crease }\end{array}$ & $\begin{array}{c}\text { De- } \\
\text { crease }\end{array}$ & \begin{tabular}{|c|}
$\begin{array}{c}\text { No } \\
\text { change }\end{array}$ \\
\end{tabular} & $\begin{array}{l}\text { Left- } \\
\text { ward }\end{array}$ & $\begin{array}{l}\text { Right- } \\
\text { ward }\end{array}$ \\
\hline $\begin{array}{l}\text { Right coronary artery } \\
\text { angiogram } \\
\text { Normal } \\
\text { Abnormal } \\
\end{array}$ & $\begin{array}{l}37 \\
13\end{array}$ & $\begin{array}{r}10 \\
8\end{array}$ & $\begin{array}{l}2 \\
1\end{array}$ & $\begin{array}{l}0 \\
0\end{array}$ & $\begin{array}{r}18 \\
7 \\
\end{array}$ & $\begin{array}{l}6 \\
4 \\
\end{array}$ & $\begin{array}{r}14 \\
4\end{array}$ & $\begin{array}{l}0 \\
0\end{array}$ & $\begin{array}{l}14 \\
11 \\
\end{array}$ & $\begin{array}{l}35 \\
10 \\
\end{array}$ & $\begin{array}{l}0 \\
0 \\
\end{array}$ & $\begin{array}{l}4 \\
4 \\
\end{array}$ & $\begin{array}{r}16 \\
4 \\
\end{array}$ & $\begin{array}{l}0 \\
0\end{array}$ \\
\hline Total & $50(74)$ & $18(26)$ & $3(11)$ & 0 & $25(89)$ & $10(36)$ & $18(64)$ & 0 & $25(36)$ & $45(64)$ & 0 & 8 (29) & $20(71)$ & 0 \\
\hline $\begin{array}{l}\text { Left coronary artery } \\
\text { angiogram } \\
\text { Normal } \\
\text { Abnormal }\end{array}$ & $\begin{array}{l}36 \\
15\end{array}$ & $\begin{array}{r}7 \\
10\end{array}$ & $\begin{array}{l}6 \\
1 \\
\end{array}$ & $\begin{array}{r}11 \\
4 \\
\end{array}$ & $\begin{array}{l}\mathbf{0} \\
\mathbf{0} \\
\end{array}$ & $\begin{array}{r}10 \\
5 \\
\end{array}$ & $\begin{array}{l}7 \\
0 \\
\end{array}$ & $\begin{array}{l}0 \\
0 \\
\end{array}$ & $\begin{array}{r}19 \\
7 \\
\end{array}$ & $\begin{array}{l}9 \\
1 \\
\end{array}$ & $\begin{array}{r}14 \\
7 \\
\end{array}$ & $\begin{array}{l}8 \\
0\end{array}$ & $\begin{array}{l}0 \\
0 \\
\end{array}$ & $\begin{array}{l}9 \\
5 \\
\end{array}$ \\
\hline Total & $\overline{51(75)}$ & $\overline{17(25)}$ & $7(32)$ & $\overline{15(68)}$ & 0 & $\overline{15(68)}$ & $\overline{7(32)}$ & 0 & $26(46)$ & $10(17)$ & $21(37)$ & $8(36)$ & 0 & $14(64)$ \\
\hline
\end{tabular}

* 3 patients with atrial fibrillation not included.

+6 patients with bilateral coronary artery response not included in left coronary artery angiogram tabulation.

in QRS amplitude was more varied during left coronary artery opacification than during opacification of the right coronary artery. Opacification of the left coronary artery produced an increase in amplitude in only 17 per cent, a decrease in 37 per cent, and no significant change in 46 per cent of patients.

Mean ST Vector. Right coronary artery opacification produced a leftward shift of the ST segment during contrast injection in 71 per cent of patients, characterized by ST segment elevation in lead I and ST segment depression in lead III; no ST segment shift occurred in the remaining patients. Left coronary artery opacification produced a rightward shift of the mean ST vector in 64 per cent of patients; in the remainder, no ST segment shift was present.

Mean $T$ Vector. Right coronary artery opacification produced a leftward shift in the mean $T$ vector in 96 per cent of patients, characterized by increased $T$ wave positivity in lead $I$ and decreased $T$ wave positivity in lead III. The one exception was a patient with almost complete right coronary artery obstruction, in whom no $T$ vector shift occurred. All patients with normal or diseased left coronary arteries had a rightward shift of the mean $T$ vector during contrast injection.

Mean $T$ Wave Amplitude. Right coronary artery opacification produced an increase in mean $T$ wave amplitude in 89 per cent of patients. The three exceptions, in whom no amplitude change was evident, included one patient with atrial fibrillation and its associated baseline fluctuations, one patient with complete, and another with almost complete, right coronary artery obstruction. Left coronary artery opacification produced an increase in mean $T$ wave amplitude in 95 per cent, all but one of the 22 patients studied.

Configuration of $T$ in Lead II. During right coronary artery opacification, all patients with normal right coronary artery arteriograms demonstrated either a decrease in the amplitude, or inversion, or deepening of inversion, of $\mathrm{T}$ waves in lead II. All but 5 of those patients with abnormal right coronary artery arteriograms demonstrated the same $T$ wave shifts. The 5 exceptions had severe bilateral coronary artery disease, and bilateral coronary artery response on left coronary artery opacification.

$Q T$ Interval. Both right and left coronary artery opacification produced QT prolongation in all patients, though not necessarily with each contrast injection. The QT prolongation was not necessarily rate related (Fig. 1). In some cases, it was probably due to prominent $U$ waves (Fig. 2).

$U$ Waves. $U$ waves were occasionally very prominent following selective opacification of either coronary artery. They were not necessarily related to rate (Fig. 2A) nor synchronous with $T$ wave changes (Fig. 2B).

Rate. Right coronary artery opacification produced heart rate slowing in 96 per cent of patients. The remaining patients did not demonstrate a change in heart rate, though significant $T$ wave shifts were evident. One of these patients had an 
III

RESPONSE TO SELECTIVE CORONARY ARTERY

OR ABNORMAL CORONARY ARTERIOGRAMS.

STRATING EACH RESPONSE IN PARENTHESIS

\begin{tabular}{|c|c|c|c|c|c|c|c|c|c|c|c|c|c|c|}
\hline \multicolumn{3}{|c|}{$\mathbf{T}$ vectort } & \multicolumn{3}{|c|}{$\mathrm{T}$ vector amplitudet } & \multicolumn{3}{|c|}{$\begin{array}{c}\text { Configuration of } T \\
\text { in lead II }\end{array}$} & \multicolumn{3}{|c|}{ QT interval } & \multicolumn{3}{|c|}{ Heart rate } \\
\hline $\begin{array}{c}\text { No } \\
\text { change }\end{array}$ & $\begin{array}{l}\text { Left- } \\
\text { ward }\end{array}$ & $\begin{array}{c}\text { Right- } \\
\text { ward }\end{array}$ & $\begin{array}{c}\text { No } \\
\text { change }\end{array}$ & $\begin{array}{c}\text { In- } \\
\text { crease }\end{array}$ & $\begin{array}{c}\text { De- } \\
\text { crease }\end{array}$ & $\begin{array}{c}\text { No } \\
\text { change }\end{array}$ & $\begin{array}{c}\text { In- } \\
\text { crease }\end{array}$ & $\begin{array}{c}\text { De- } \\
\text { crease }\end{array}$ & $\begin{array}{c}\text { No } \\
\text { change }\end{array}$ & $\begin{array}{c}\text { In- } \\
\text { crease }\end{array}$ & $\begin{array}{c}\text { De- } \\
\text { crease }\end{array}$ & $\begin{array}{c}\text { No } \\
\text { change }\end{array}$ & $\begin{array}{c}\text { In- } \\
\text { crease }\end{array}$ & $\begin{array}{c}\text { De- } \\
\text { crease }\end{array}$ \\
\hline $\begin{array}{l}0 \\
1\end{array}$ & $\begin{array}{r}20 \\
7\end{array}$ & $\begin{array}{l}0 \\
0\end{array}$ & $\begin{array}{l}\mathbf{1} \\
\mathbf{2}\end{array}$ & $\begin{array}{r}19 \\
6\end{array}$ & $\begin{array}{l}0 \\
0\end{array}$ & $\begin{array}{l}\mathbf{0} \\
\mathbf{0}\end{array}$ & $\begin{array}{l}0 \\
5\end{array}$ & $\begin{array}{l}49 \\
16\end{array}$ & $\begin{array}{l}0 \\
0\end{array}$ & $\begin{array}{l}50 \\
21\end{array}$ & $\begin{array}{l}0 \\
0\end{array}$ & $\begin{array}{l}3 \\
0\end{array}$ & $\begin{array}{l}\mathbf{0} \\
\mathbf{0}\end{array}$ & $\begin{array}{l}47 \\
21\end{array}$ \\
\hline $1(4)$ & $27(96)$ & 0 & $3(11)$ & $25(89)$ & 0 & 0 & $5(7)$ & 65(93) & 0 & $71(100)$ & 0 & $3(4)$ & 0 & $68(96)$ \\
\hline $\begin{array}{l}\mathbf{0} \\
\mathbf{0}\end{array}$ & $\begin{array}{l}0 \\
0\end{array}$ & $\begin{array}{r}17 \\
5\end{array}$ & $\begin{array}{l}1 \\
0\end{array}$ & $\begin{array}{r}16 \\
5\end{array}$ & $\begin{array}{l}\mathbf{0} \\
\mathbf{0}\end{array}$ & $\begin{array}{l}0 \\
0\end{array}$ & $\begin{array}{l}42 \\
15\end{array}$ & $\begin{array}{l}\mathbf{0} \\
\mathbf{0}\end{array}$ & $\begin{array}{l}\mathbf{0} \\
\mathbf{0}\end{array}$ & $\begin{array}{l}44 \\
27\end{array}$ & $\begin{array}{l}0 \\
0\end{array}$ & $\begin{array}{l}1 \\
4 \\
\end{array}$ & $\begin{array}{l}\mathbf{0} \\
\mathbf{0}\end{array}$ & $\begin{array}{l}43 \\
23 \\
\end{array}$ \\
\hline 0 & 0 & $22(100)$ & $1(5)$ & 21(95) & 0 & 0 & $57(100)$ & 0 & $\mathbf{0}$ & $71(100)$ & 0 & $5(7)$ & 0 & $66(93)$ \\
\hline
\end{tabular}

¥ 1 patient with bilateral coronary artery response not included in right coronary artery angiogram tabulation.

$\$ 14$ patients with bilateral coronary artery response not included in left coronary artery angiogram tabulation.

unusually large right coronary artery with less than optimal opacification. The others had good opacification and no evident basis for the absence of rate slowing. Left coronary artery opacification produced heart rate slowing in 93 per cent of patients. The patients who did not evidence rate slowing did have QT prolongation and $\mathrm{T}$ wave changes during left coronary artery opacification. Bradycardia generally reverted easily to the previous rhythm with cessation of contrast injection and vigorous coughing by the patient.

Asystole of longer than 4 seconds occurred in 4 patients, all during right coronary artery injection. The two of longest duration, 45 and 16 seconds, respectively, occurred early in our experience, and responded readily to a few seconds of closed chest cardiac massage. Ventricular fibrillation occurred twice, both times during right coronary artery opacification. The arrhythmia was not secondary to prolonged asystole. Both patients were immediately converted to sinus rhythm with direct current countershock across the intact chest and there were no sequelæ.

Ancemia. Only 2 patients had hæmoglobin levels below $11.0 \mathrm{~g}$. They both demonstrated a normal electrocardiographic response to selective coronary artery opacification.

Hypertrophy. There was radiological or electrocardiographic evidence of ventricular enlargement in 35 per cent of patients. All had normal right coronary artery responses. There was evidence of hypertrophy in 35 per cent of those with bilateral coronary artery responses.

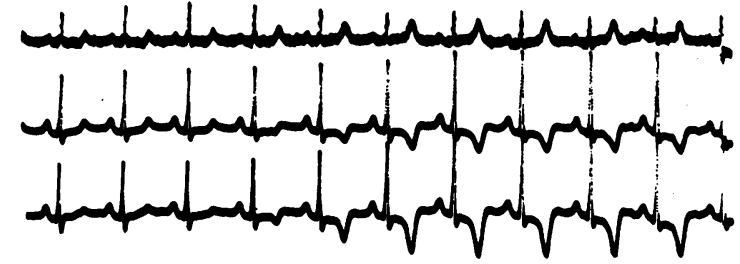

FIg. 1.-The QRS, ST, and $T$ changes following selective right coronary artery opacification are shown to occur in the absence of rate changes. Leads I, II, and III are inscribed from above downward.
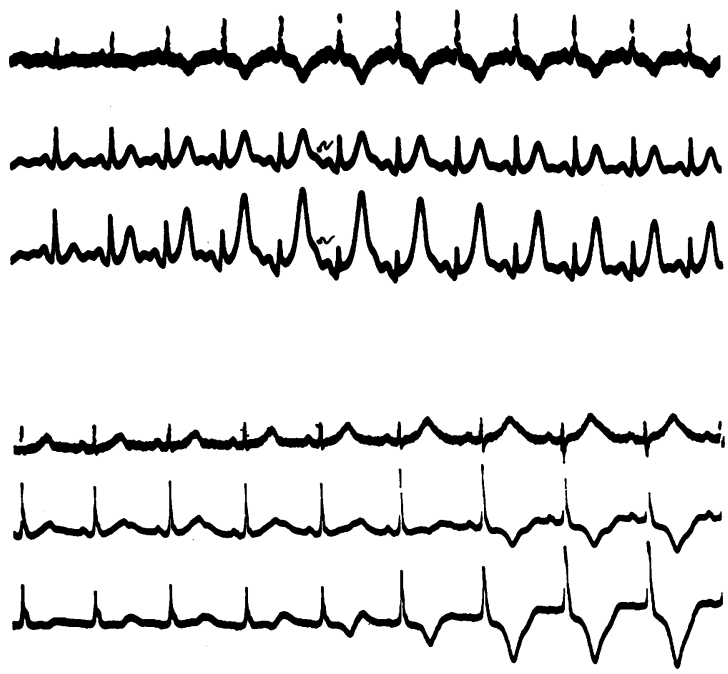

FIG. 2.-Prominent $U$ waves following selective left coronary artery opacification are shown to be independent of rate changes (above). Prominent $U$ waves following selective right coronary artery opacification are shown to be independent of $T$ wave changes (below). Leads I, II, and III are inscribed from above downward. 


\section{Discussion}

Selective opacification of the right or left coronary arteries is associated with reproducible electrocardiographic changes which will be considered in four groups: (1) changes common to both right and left coronary artery opacification; (2) changes characteristic of right coronary artery opacification; (3) changes characteristic of left coronary artery opacification; and (4) bilateral electrocardiographic response to right or left coronary artery opacification.

(1) Electrocardiographic Changes Common to Both Right and Left Coronary Artery Opacification. A decrease in $\mathbf{P}$ wave amplitude occurred in approximately 20 per cent of patients with normal right and left coronary arteriograms; there was no evident difference in the response to either right or left coronary artery opacification. Twice as many patients with abnormal coronary arteriograms had a transient decrease in $\mathbf{P}$ wave amplitude. A decrease in $\mathrm{P}$ wave amplitude with both right and left coronary artery injection was evident in 13 of the 22 patients who showed this change. Of these 13 patients, $8(62 \%)$ had abnormal coronary arteriograms. Only one patient, a 42-year old man with a secundum type of atrial septal defect, had an increase in $\mathbf{P}$ wave amplitude.

Whether coronary artery obstructive disease increases the size and/or number of vessels to the atria is unclear.

Mean frontal plane QRS amplitude increased or was unchanged following both right and left coronary artery opacification. More variable changes, including decrease in QRS amplitude, were noted when only lead II was studied. This is not surprising when it is recalled that the mean frontal QRS vector may increase in magnitude at the same time that it shifts away from the lead II axis. Amplitude increases were greatest when maximal opacification was obtained. This may be the reason for a higher incidence of QRS amplitude increase following right coronary artery injection, since the right coronary artery sometimes seemed to opacify better than the left.

$\mathrm{T}$ wave amplitude, as determined by simultaneous bipolar leads, increased in almost all patients. In the four patients in whom $T$ wave changes were not evident, two had complete or almost complete occlusion of the injected artery, and one had atrial fibrillation with an irregular baseline which may have obscured small $T$ wave changes.

The QT interval increased in at least one opacification of both left and right coronary artery arteriograms in every patient. This change was not necessarily rate related, but may in some cases have been due to prominent superimposed $U$ waves.
The heart rate decreased in most patients and remained constant in the others. A transient speeding of the heart rate sometimes followed bradycardia, but did not occur in its absence.

(2) Electrocardiographic Changes Characteristic of Right Coronary Artery Opacification. Changes characteristic of right or left coronary artery opacification were limited to mean QRS, ST, and T vector shifts, as identified in the frontal plane by means of simultaneous recording of leads I, II, and III, or, to a lesser extent, lead II alone. The characteristic response is a smooth shift in the mean QRS vector to the right and simultaneous $S T$ and $T$ vector shifts to the left (Fig. 3).
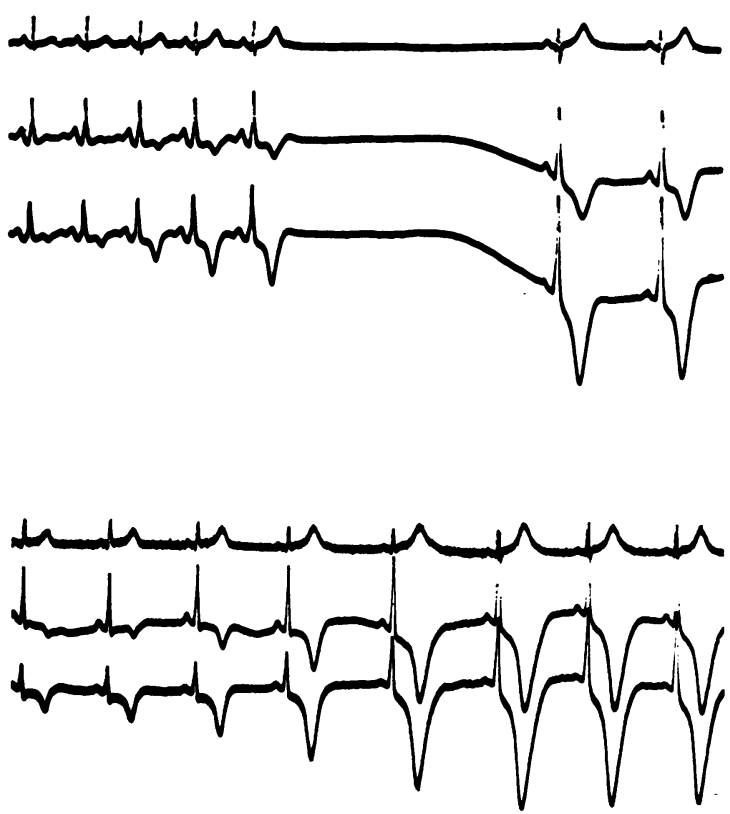

FIG. 3.-Two examples of the characteristic electrocardiographic response to selective right coronary artery opacification. Leads I, II, and III are inscribed from above downward.

The amplitude of the QRS complex in lead II increased or remained unchanged in all patients following right coronary artery opacification. The $T$ wave in lead II decreased in amplitude, and became inverted, or more deeply inverted, in 65 of 70 patients. The remaining 5 patients revealed an increase in positivity of the $T$ wave in lead II. All 5 of these patients had a bilateral coronary artery response to left coronary artery opacification, and gross coronary artery obstruction. 
(3) Electrocardiographic Changes Characteristic of Left Coronary Artery Opacification. The characteristic electrocardiographic response to left coronary artery opacification is a smooth shift in the mean QRS vector to the left with simultaneous ST and $T$ vector shifts to the right (Fig. 4). The amplitude change in the lead II QRS complex was variable, increasing, decreasing, or remaining unchanged. The $T$ wave in lead II became positive or less inverted in all cases.
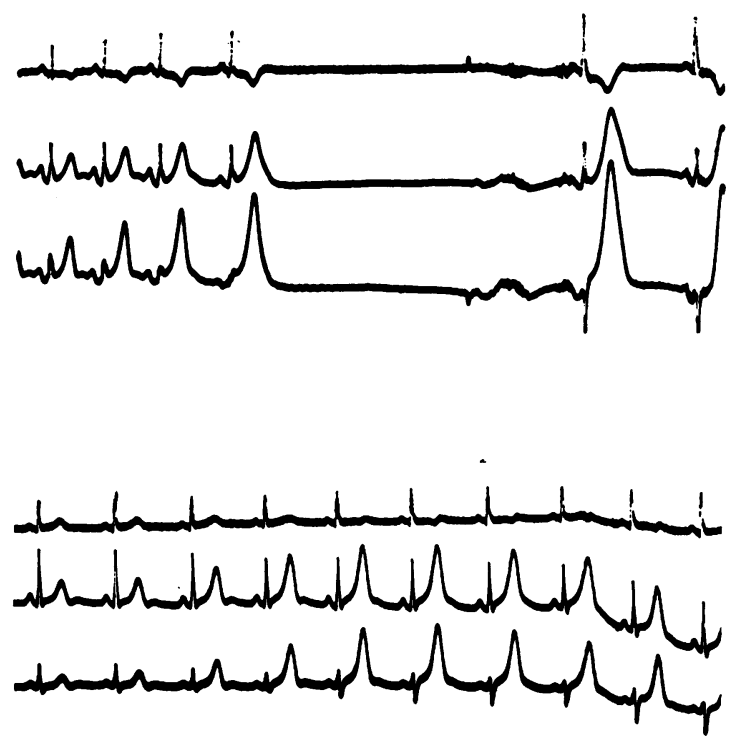

FIG. 4.-Two examples of the characteristic electrocardiographic response to selective left coronary artery opacification. Leads I, II, and III are inscribed from above downward.

(4) Bilateral Electrocardiographic Response to Right or Left Coronary Artery Opacification. During coronary artery opacification, 15 patients had cardiographic changes different from those described above. The initial QRS, ST, and T wave changes in 14 patients were characteristic of the changes anticipated in the vessel being opacified as described above. The changes then reversed themselves and were more characteristic of changes associated with opacification of the contralateral vessel. This suggested that contrast media, after a short delay, was perfusing portions of the heart normally supplied by the contralateral vessel (Fig. 5).

The exceptional patient, the only one with a bilateral response to right coronary artery opacification, initially had $T$ wave shifts usually seen following left coronary artery opacification, with a subsequent reversal to the changes seen with right coronary artery opacification (Fig. 6). It is

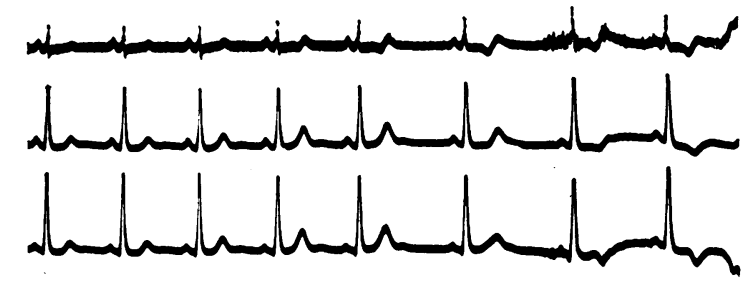

Fig. 5.-Two examples of the bilateral coronary artery response to selective left coronary artery opacification. Leads

I, II, and III are inscribed from above downward.

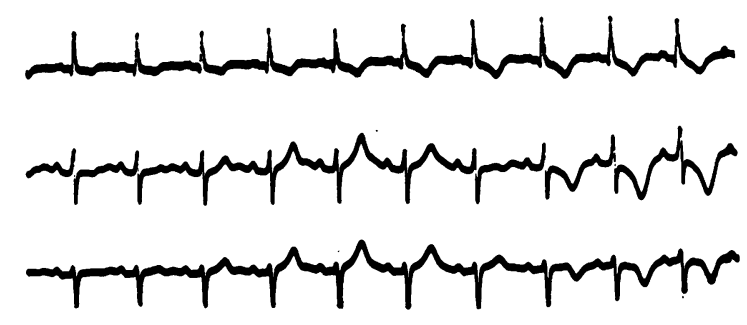

interesting that a large intercoronary anastomotic vessel opacified during right coronary artery injection.

These changes were noted in 14 patients with left coronary artery opacification and one patient with right coronary artery opacification. In no patient was this response present with opacification of both arteries. All but one of these 15 patients revealed gross arterial disease with obstruction of at least 50 per cent of estimated lumen diameter of one or more major vessels. Complete obstruction of at least one major vessel was present in 6 patients. Of the 15 patients, 7 showed very prominent collateral flow around the obstructed vessel. The one patient whose coronary arteriogram revealed no obstruction had calcific aortic stenosis with a 145 $\mathrm{mm}$. Hg systolic pressure gradient across the valve at rest, and both electrocardiographic and radiological evidence of left ventricular hypertrophy.

Sensitivity of Response. QT prolongation and $T$ wave changes were the most sensitive changes,

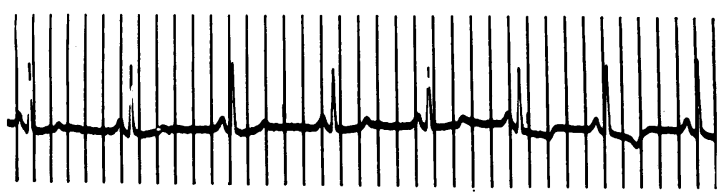

FIG. 6.-The bilateral response to selective right coronary artery opacification. Lead II only. 
occurring at least once with opacification of each vessel in all patients. A decrease in heart rate occurred in 95 per cent of patients, including the 3 with atrial fibrillation. QRS vector shifts, QRS amplitude changes, and ST shifts occurred in the majority of patients. Decreases in $\mathrm{P}$ wave amplitude were the least sensitive, occurring in less than 25 per cent of patients. The most prominent $T$ wave changes were usually associated with $P, Q R S$, and ST changes, though this was not always the case. ST shifts appeared to be intimately associated with $T$ wave shifts, but because of the low amplitude, were not as evident with lesser $T$ wave amplitude shifts.

Sequence of Response. QRS, ST, T, and QT changes were closely associated. $\mathbf{P}$ wave amplitude changes often lagged several beats behind changes in ventricular depolarization and repolarization.

Clinical Significance. Zoll, James, and others (Zoll, Wessler, and Schlesinger, 1951; Baroldi, Mantero, and Scomazzoni, 1956; James, 1960, 1961 ; Fulton, 1964a, b) have demonstrated intercoronary and intracoronary artery anastomotic channels in the post-mortem study of normal hearts. These channels were found to be larger in diseased hearts, particularly in association with coronary artery disease or ventricular hypertrophy.

Serial responses suggestive of segmental opacification of both coronary arteries were present in 15 patients. These changes suggest that the contrast medium first perfused the myocardium that the artery usually supplied, then perfused at least a portion of the myocardium most commonly supplied by the other major coronary artery. Of the 15 patients with bilateral coronary artery response, 14 had marked obstructive disease of the major coronary arteries; 5 of the 15 had ventricular hypertrophy evident by electrocardiographic or radiological evaluation. All of the 15 patients had conspicuous coronary obstructive disease and/or evidence of ventricular hypertrophy. Of these 15 patients with bilateral responses, 6 had large collateral vessels, evident on selective coronary cine-arteriography.

These relationships suggest that the bilateral electrocardiographic response to selective coronary artery opacification is a response indicating the existence of intercoronary anastomotic channels. Persons with a diminutive right coronary artery and dominant perfusion of the right heart from branches of the left coronary artery might conceivably demonstrate the bilateral electrocardiographic response to selective left coronary artery opacification, but such a phenomenon was not evident in this study.

\section{SUMMARY}

The electrocardiographic changes recorded during the study of 71 patients by selective coronary arteriography are presented. The electrocardiogram was monitored continuously during and immediately following contrast injection with warm Hypaque R.

The electrocardiographic changes common to both right and left coronary artery injection were characterized by a decrease in $P$ wave amplitude, an increase in mean frontal QRS amplitude, an increase in the mean $T$ vector amplitude, and a shift in the mean ST and T vector away from the mean QRS vector. The heart rate slowed and the $\mathrm{QT}$ interval increased.

The electrocardiographic changes of right coronary artery opacification were characterized by a smooth shift of the mean QRS vector to the right and simultaneous shifts of the mean ST and T vectors to the left. These changes were termed "right coronary artery response".

The electrocardiographic changes of left coronary artery opacification were characterized by a smooth shift of the mean QRS vector to the left and simultaneous shifts of the mean ST and T vectors to the right. These changes were termed "left coronary artery response".

Electrocardiographic changes revealing characteristics of both the left and right coronary artery response were noted in 15 patients. These changes were initially those of left coronary artery response and then changed to vector shifts seen in right coronary artery opacification. There were, therefore, two major QRS-ST-T vector shifts during selective opacification of one coronary artery. Of the 15 patients who demonstrated this response, 14 had evidence of significant coronary arterial obstructive disease. These changes were termed "bilateral coronary artery response". Seven of the 15 patients demonstrated prominent collateral flow around the obstructed artery. The one patient who did not have evidence of coronary obstruction had calcific aortic stenosis, with a peak systolic pressure gradient across the aortic valve of $145 \mathrm{~mm}$. $\mathrm{Hg}$, and electrocardiographic and radiological evidence of left ventricular hypertrophy.

The bilateral coronary artery response in 15 patients suggests that contrast medium perfused the myocardium which the artery usually supplies (with the one exception noted above), then perfused at least a portion of the myocardium most commonly supplied by the other major coronary artery. The bilateral electrocardiographic response to selective coronary artery opacification suggests the existence of intercoronary anastomotic channels. 


\section{REFERENCES}

Baroldi, G., Mantero, O., and Scomazzoni, G. (1956). The collaterals of the coronary arteries in normal and pathological hearts. Circulat. Res., 4, 223.

Fulton, W. F. M. (1964a). Anastomotic enlargement and ischæmic myocardial damage. Brit. Heart $\mathcal{F}$., 26, 1.

- (1964b). The dynamic factor in enlargement of coronary arterial anastomoses, and paradoxical changes in the subendocardial plexus. Brit. Heart f., 26, 39.

James, T. N. (1960). Anatomy of the heart: normal and pathologic, as related to cardiac function. In Clinical Cardiopulmonary Physiology, ed. B. L. Gordon, 2nd edn., p. 8. (American College of Chest Physicians.) Grune and Stratton, New York.
(1961). Anatomy of the Coronary Arteries. Paul B. Hoeber, New York.

Likoff, W., Kasparian, H., Lehman, J. S., and Segal, B. L. (1964). Evaluation of "coronary vasodilators" by coronary arteriography. Amer. f. Cardiol., 13, 7.

Littmann, D. (1962). Coronary arteriography. Amer. $\mathcal{F}$. Cardiol., 9, 410.

Ross, R. S. (1963). Clinical applications of coronary arteriography. Circulation, 27, 107.

Sones, F. M., Jr., and Shirey, E. K. (1962). Cine coronary arteriography. Mod. Conc. cardiovasc. Dis., 31, 735.

Zoll, P. M., Wessler, S., and Schlesinger, M. J. (1951). Interarterial coronary anastomoses in the human heart, with particular reference to anemia and related cardiac anoxia. Circulation, 4, 797. 